\title{
Increased expression of mitochondrial DNA-encoded genes in human renal mesangial cells in response to high glucose-induced reactive oxygen species
}

\author{
GHADA AL-KAFAJI $^{1}$, MOHAMED ABDALLA SABRY ${ }^{2}$ and MOIZ BAKHIET $^{1}$ \\ Departments of ${ }^{1}$ Molecular Medicine and ${ }^{2}$ Biochemistry, College of Medicine and Medical Sciences, \\ Arabian Gulf University, Manama 26671, Bahrain
}

Received February 22, 2015; Accepted November 17, 2015

DOI: $10.3892 / \mathrm{mmr} .2015 .4732$

\begin{abstract}
Reactive oxygen species (ROS)-mediated disruption of mitochondrial respiratory function has been implicated in the complications of diabetes. The present study examined changes in the gene expression of mistochondrial DNA (mtDNA)-encoded subunits of electron transport chain complexes in response to high glucose-induced ROS overproduction in an in vitro model of diabetic nephropathy using human renal mesangial cells. Mitochondrial ROS generation was assessed by confocal microscopy and flow cytometry in the cells following culture in 5 and $25 \mathrm{mM}$ glucose. The mRNA expression levels of nicotinamide adenine dinucleotide dehydrogenase 2 (ND2) of complex I, cytochrome $b$ (CYTB) of complex III, cytochrome $c$ oxidase (COI) of complex IV and ATPase 6 of complex V were analyzed by reverse transcription-quantitative polymerase chain reaction. The protein expression levels of ND2, CYTB, COI and ATPase 6 were analyzed by western blotting. A significant increase in mitochondrial ROS production was observed in the cells cultured in $25 \mathrm{mM}$ glucose, compared with cells cultured in $5 \mathrm{mM}$ glucose $(\mathrm{P}<0.05)$. The mRNA expression of ND2, CYTB, $\mathrm{CO} 1$ and ATPase 6 was significantly increased following culture in $25 \mathrm{mM}$ glucose, compared with the cells cultured in $5 \mathrm{mM}$ glucose $(\mathrm{P}<0.05)$. This increase in mRNA expression was accompanied by significant increases in protein expression following incubation in $25 \mathrm{mM}$ glucose $(\mathrm{P}<0.05)$. The increase in mtDNA-encoded gene expression in the electron transport subunits following exposure to high glucose-induced ROS may be a compensatory response mechanism for the
\end{abstract}

Correspondence to: Dr Ghada Al-kafaji, Department of Molecular Medicine, College of Medicine and Medical Sciences, Arabian Gulf University, Salmaniya Avenue, Building 293, Road 2904, Block 329, Manama 26671, Bahrain

E-mail: ghadaa@agu.edu.bh

Key words: mitochondrial DNA-encoded gene expression, electron transport chain complexes, human renal mesangial cells, diabetic nephropathy, reactive oxygen species decline in mitochondrial function, which may be important in the development of diabetic nephropathy through enhanced ROS generation.

\section{Introduction}

Hyperglycemia has been shown to cause several of the pathological consequences of type 1 and type 2 diabetes mellitus (1). It is well-established that hyperglycemia results in reactive oxygen species (ROS) overproduction through increased input of metabolic substrate into the mitochondria, which deregulates the electron transport system (1). ROS are produced by various aerobic metabolism signaling pathways; however, the primary source of their production is the mitochondria, which produce ROS as a by-product of the electron transport chain (ETC) during cellular respiration $(2,3)$. The elevated production of ROS by the mitochondrial respiratory chain during hyperglycemia has been suggested as a key initiator of tissue damage in diabetes-associated microvascular complications, including diabetic nephropathy $(1,4)$.

Mammalian mitochondria possess their own genome, which consists of a single, circular double-stranded mitochondrial DNA (mtDNA) molecule of 16,569 base pairs (5). mtDNA encodes essential components of complexes of the ETC, including seven nicotinamide adenine dinucleotide dehydrogenase (ND) subunits (ND1, ND2, ND3, ND4, ND4L, ND5 and ND6) of NADH dehydrogenase (complex I), the cytochrome $b$ (CYTB) subunit of the ubiquinol-cytochrome $c$ oxidoreductase (complex III), three subunits (COI, COII and COIII) of cytochrome $c$ oxidase (complex IV) and the ATPase 6 and 8 subunits of complex $\mathrm{V}$, as well as ribosomal and transfer RNAs, which are necessary for protein production within the mitochondria $(6,7)$.

mtDNA is prone to oxidative damage and several factors are considered to contribute to the enhanced susceptibility of mtDNA to this damage $(7,8)$. mtDNA is located in the matrix, which is in proximity to the ROS-generating respiratory chain; it lacks an efficient DNA repair mechanism and protective proteins, including histones $(7,8)$. Therefore mtDNA, which encodes the majority of respiratory chain proteins, is continuously subjected to ROS attack. The accumulation of oxidative damage to mtDNA and mitochondria may induce a 
respiratory defect, which increases the leakage of ROS from the ETC, leading to an increase in the production of ROS in the mitochondria and the induction of further oxidative damage (9).

Deficits in the activity of the ETC enzymes and mitochondria have been reported in several diseases where oxidative stress is important (9-12), and are associated with altered expression of mtDNA-encoded genes or mtDNA content with age $(13,14)$.

Oxidative stress and hyperglycemia-induced disturbance of various mitochondrial functions have been linked to diabetes and its complications $(15,16)$. Furthermore, changes in the activities of mitochondrial complexes have been associated with renal dysfunction in the kidney of diabetic rats during the early stages of diabetes (17).

Considering the importance of mitochondria and ETC complexes in the generation of ROS during hyperglycemia in diabetic complications, the present study aimed to examine changes in the expression of mtDNA-encoded genes of respiratory chain complex enzymes in human renal mesangial cells in response to high glucose-induced ROS overproduction. The concept that oxidative stress, primarily driven by mitochondrial superoxide, underlies diabetic complications means that interventions and therapies that modify mitochondrial function may aid in the development of new treatments for diabetes-associated complications.

\section{Materials and methods}

Cell culture. Human renal mesangial cells (cat. no. 4200) were obtained from ScienCell Research Laboratories (Carlsbad, CA, USA), and maintained in Dulbecco's modified Eagle's medium (DMEM; Sigma-Aldrich, St. Louis, MO, USA) supplemented with $10 \mathrm{mmol} / 1$ HEPES, 20\% fetal bovine serum, $100 \mathrm{U} / \mathrm{ml}$ penicillin and $100 \mu \mathrm{g} / \mathrm{ml}$ streptomycin (Sigma-Aldrich) in a humidified atmosphere containing $5 \% \mathrm{CO}_{2}$ at $37^{\circ} \mathrm{C}$, as previously described (18-20). Cells from the third to sixth passage were grown to confluence. Prior to seeding, the growth was arrested in serum-free medium for $24 \mathrm{~h}$ to favor the selection of quiescent cells. The cells were then seeded in triplicate at a density of $1 \times 10^{6}$ in DMEM media supplemented with either $5 \mathrm{mM}$ glucose (normal glucose) or $25 \mathrm{mM}$ glucose (high glucose). The cells were incubated for $24 \mathrm{~h}$ at $37^{\circ} \mathrm{C}$, and were used for the subsequent ROS assay, and assessment of RNA and protein expression levels.

Detection of mitochondrial ROS using confocal microscopy and flow cytometry. The mitochondrial fluorogenic dye, MitoSOX red probe (Invitrogen; Thermo Fisher Scientific, Inc., Waltham, MA, USA), was used to assess mitochondrial ROS production in the human renal mesangial cells using confocal microscopy, as previously described (18). This probe selectively targets mitochondria and is readily oxidized by superoxide. The synchronized quiescent cells were seeded onto glass coverslips and incubated for $24 \mathrm{~h}$ at $37^{\circ} \mathrm{C}$ in $5 \mathrm{mM}$ glucose (normal glucose) or $25 \mathrm{mM}$ glucose (high glucose) The cells were then loaded with MitoSOX red $(5 \mathrm{mM})$ for $20 \mathrm{~min}$ at $37^{\circ} \mathrm{C}$, and washed three times with warm phosphate-buffered saline (PBS). Images of the cells were captured using a Zeiss LSM 510 confocal laser microscope (Zeiss AG,
Oberkochen, Germany) at an excitation wavelength of $514 \mathrm{~nm}$ and an emission wavelength of $560 \mathrm{~nm}$.

Zeiss software (version 3.2; Zeiss AG) was used to calculate the mean fluorescence intensity of the MitoSOX red $/ \mathrm{mm}^{2}$ cell area.

To perform flow cytometric analysis of mitochondrial ROS, the cells were incubated with either 5 or $25 \mathrm{mM}$ glucose for $24 \mathrm{~h}$ at $37^{\circ} \mathrm{C}$, washed with warm PBS, and loaded with $5 \mathrm{mM}$ MitoSOX red for $20 \mathrm{~min}$ at $37^{\circ} \mathrm{C}$. Following incubation, the cells were washed again with PBS, collected by centrifugation $\left(500 \mathrm{x} \mathrm{g}\right.$ for $5 \mathrm{~min}$ at $\left.25^{\circ} \mathrm{C}\right)$, and then resuspended in PBS. The cells were analyzed at $514 \mathrm{~nm}$ excitation to measure oxidized MitoSOX red, and with a $560 \mathrm{~nm}$ barrier filter using a flow cytometer (FACScan; BD Biosciences, Franklin Lakes, NJ, USA).

RNA extraction and cDNA preparation. Total RNA (5 mg) was isolated from the human renal mesangial cells using TRIzol ${ }^{\circledR}$ reagent (Invitrogen; Thermo Fisher Scientific, Inc.), according to the manufacturer's protocol. All RNA samples were treated with DNase using a TURBO DNA-free ${ }^{\mathrm{TM}}$ kit (Invitrogen; Thermo Fisher Scientific, Inc.) and were reverse transcribed to cDNA, as previously described $(19,20)$. The cDNA samples were stored at $-20^{\circ} \mathrm{C}$ until usage.

Primers and reverse transciption-polymerase chain reaction (RT-PCR). Primers for ND2, CYTB, COI and ATPase 6 (Table I), encoded by the mitochondrial genome were designed using National Center for Biotechnology Information database (http://www.ncbi.nlm.nih.gov/), in accordance with the human mtDNA sequence. The housekeeping gene, $\beta$-actin, was used as an internal control (Table I). All primers were synthesized by Sigma-Aldrich. RT-PCR was performed using a OneStep RT-PCR kit (Qiagen GmbH, Hilden, Germany). The reaction mixture (25 $\mu$ l total volume) contained reverse transcription buffer $(10 \mathrm{X})$, dNTP mix $(100 \mathrm{mM})$, forward and reverse primers (50 ng/ $\mu \mathrm{l}$ each), cDNA (10 ng) and heat-stable Taq DNA polymerase $(500 \mathrm{U} / \mu \mathrm{l})$. The amplification reactions were performed in 30 cycles using an automated thermal cycler (2400; PerkinElmer, Inc., Waltham, MA, USA) with the following thermocycling conditions: Denaturation at $95^{\circ} \mathrm{C}$ for $5 \mathrm{~min}$, annealing for $1.5 \mathrm{~min}$ and extension at $70^{\circ} \mathrm{C}$ for $7 \mathrm{~min}$. The annealing temperature of each primer is presented in Table I.

$R T-q P C R$. The mRNA expression levels of mtDNA-encoded ND2, CYTB, COI and ATPase 6 were determined using RT-qPCR. Prior to RT-qPCR, standards in a dilution series, containing between $1 \times 10^{7}$ and $1 \times 10^{2}$ copies $/ \mu 1$ of each gene, were prepared from the purified RT-PCR products, and were used as calibration curves in the RT-qPCR runs. RT-qPCR was performed using a FastStart DNA Master plus $S Y B R^{\circledR}$ Green 1 kit (Roche Diagnostics, Basel, Switzerland). The reaction mix contained SYBR ${ }^{\circledR}$ Green 1 probe, cDNA (10 ng), forward and reverse primers $(50 \mathrm{ng} / \mu \mathrm{l}$ each) and nuclease-free water to a final volume of $10 \mu \mathrm{l}$. All reactions were performed using an Applied Biosystems 7900HT Fast Real Time PCR system with the following thermocycling conditions: $95^{\circ} \mathrm{C}$ for $10 \mathrm{~min}$, followed by $95^{\circ} \mathrm{C}$ for $15 \mathrm{sec}$ and $60^{\circ} \mathrm{C}$ for $60 \mathrm{sec}$ for a total of 40 cycles. The concentrations of mtDNA-encoded ND2, CYTB, COI and ATPase 6 were converted to copy numbers, 
Table I. Primer sequences of mitochondrial ND2, CYTB, COI, ATPase 6 and nuclear $\beta$-actin.

\begin{tabular}{|c|c|c|c|}
\hline Target gene & Primer sequence $\left(5^{\prime}-3^{\prime}\right)$ & $\begin{array}{l}\text { Size of PCR } \\
\text { product (bp) }\end{array}$ & $\begin{array}{c}\text { Annealing } \\
\text { temperature }\left({ }^{\circ} \mathrm{C}\right)\end{array}$ \\
\hline ND2 & $\begin{array}{l}\text { Forward, CACAGAAGCTGCCATCAAGTA } \\
\text { Reverse, CCGGAGAGTATATTGTTGAAGAG }\end{array}$ & 89 & 62 \\
\hline CYTB & $\begin{array}{l}\text { Forward, TCATCGACCTCCCCACCCCATC } \\
\text { Reverse, CGTCTCGAGTGATGTGGGCGATT }\end{array}$ & 165 & 58 \\
\hline COI & $\begin{array}{l}\text { Forward, TCATGATCACGCCCTCATA } \\
\text { Reverse, CATCGGGGTAGTCCGAGTAA }\end{array}$ & 222 & 60 \\
\hline ATPase 6 & $\begin{array}{l}\text { Forward, GCCCTAGCCCACTTCTTACC } \\
\text { Reverse, TTAAGGCGACAGCGATTTCT }\end{array}$ & 256 & 60 \\
\hline$\beta$-actin & $\begin{array}{l}\text { Forward, ACAGAGCCTCGCCTTTGC } \\
\text { Reverse, GTTGGCCTTGGGGTTCAGG }\end{array}$ & 399 & 65 \\
\hline
\end{tabular}

PCR, polymerase chain reaction; ND2, nicotinamide adenine dinucleotide dehydrogenase 2; CYTB, cytochrome $b$; COI, cytochrome $c$ oxidase.

with the values expressed relative to that of $\beta$-actin (19-21). All reactions were performed in duplicate.

SDS-PAGE and western blot analyses. SDS-PAGE and immunoblotting were performed, as previously described (19). Briefly, cells were lysed with $0.4 \mathrm{ml}$ of radioimmunoprecipitation buffer (Santa Cruz Biotechnology, Inc., Dallas, TX, USA) containing a protease inhibitor cocktail, on ice for $10 \mathrm{~min}$. Lysates were centrifuged at $12,000 \mathrm{x}$ g for $5 \mathrm{~min}$ at $4^{\circ} \mathrm{C}$, and the supernatants were collected. The supernatants containing the protein were recovered and assayed for total protein using a bicinchoninic acid assay kit (Pierce Biotechnology, Inc., Rockford, IL, USA) according to the manufacturer's instructions. Prior to separation on gel, samples were boiled for $5 \mathrm{~min}$ followed by cooling at room temperature for $5 \mathrm{~min}$. Equal quantities of proteins $(25 \mu \mathrm{g})$ were separated using $10 \%$ SDS-PAGE (Sigma-Aldrich) and transferred onto polyvinylidene difluoride membranes (Thermo Fisher Scientific, Inc.). The membranes were then blocked with 5\% skimmed milk in PBS containing 0.1\% Tween 20 (Thermo Fisher Scientific, Inc.) for $1 \mathrm{~h}$ prior to being incubated overnight at $4^{\circ} \mathrm{C}$ with the following primary antibodies: Rabbit polyclonal anti-ND2 (1:500; sc-20495-R; Santa Cruz Biotechnology, Inc.), rabbit polyclonal anti-CYTB (1:500; sc-11436, Santa Cruz Biotechnology, Inc.), goat polyclonal anti-COI (1:5,000; sc-23982; Santa Cruz Biotechnology, Inc.) and mouse monoclonal anti-ATPase 6 (1:1,000; MA3-929; Thermo Fisher Scientific, Inc.). Following washing with PBS-Tween 20, the membranes were incubated for $1 \mathrm{~h}$ at $4^{\circ} \mathrm{C}$ with the following secondary antibodies: Horseradish peroxidase (HRP)-conjugated goat anti-rabbit IgG (1:5,000; sc-2004; Santa Cruz Biotechnology, Inc.), HRP-conjugated donkey anti-goat IgG (1:5,000; sc-2020; Santa Cruz Biotechnology, Inc.), HRP-conjugated goat anti-mouse IgG (1:10,000; 31430; Thermo Fisher Scientific, Inc.) and HRP-conjugated mouse anti- $\beta$-actin (1:500; sc-47778; Santa Cruz Biotechnology, Inc.). Immunoreactive bands were detected by enhanced chemiluminescence (Pierce Biotechnology, Inc., Rockford,
IL, USA) and the immunoreactive bands, corresponding to the correct molecular mass of the target protein, were quantified by densitometry using Image J software (version 1.46r; National Institutes of Health, Bethesda, MA, USA). The values were normalized to internal $\beta$-actin, which also served as a loading control, in order to make relative comparisons.

Statistical analysis. Data were analyzed using SPSS 19 statistical software (IBM SPSS, Armonk, NY, USA). An independent samples t-test was performed to compare the mean expression levels of mtDNA-encoded genes in the cells for each treatment condition. The results are expressed as the mean \pm standard deviation. $\mathrm{P}<0.05$ was considered to indicate a statistically significant difference.

\section{Results}

High glucose induces an increase in mitochondrial ROS production. The production of mitochondrial ROS was assessed in human renal mesangial cells cultured for $24 \mathrm{~h}$ in $5 \mathrm{mM}$ glucose (normal glucose) and $25 \mathrm{mM}$ glucose (high glucose) by confocal microscopy and flow cytometry, following staining with the mitochondrial specific probe, MitoSOX red.

The confocal microscopic imaging showed an increase in MitoSOX red fluorescence signal in the cells cultured in $25 \mathrm{mM}$ glucose, compared with the cells cultured in $5 \mathrm{mM}$ glucose, suggesting increased mitochondrial ROS production in these cells. No fluorescence signal was detected in the cells cultured in $5 \mathrm{mM}$ glucose (Fig. 1A). Furthermore, histograms of the results of FACS analysis showed an increase in the mean fluorescence intensity of MitoSOX in the cells cultured in $25 \mathrm{mM}$ glucose, compared with those cultured in $5 \mathrm{mM}$ glucose (Fig. 1B). Quantitative measurements of the mean fluorescence intensities demonstrated a 6.5-fold increase in MitoSOX red fluorescence intensity in the $25 \mathrm{mM}$ glucose-treated cells, compared with the cells treated with $5 \mathrm{mM}$ glucose $(\mathrm{P}<0.05$; Fig. 1C). 
A

\section{$5 \mathrm{mM}$ glucose}

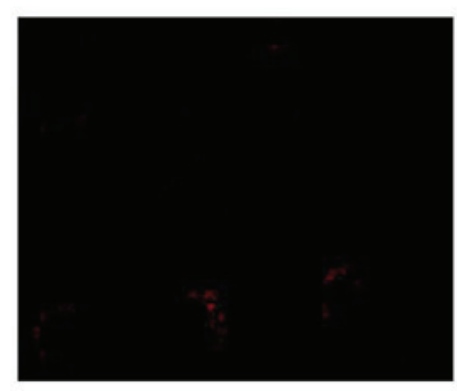

$5 \mathrm{mM}$ glucose
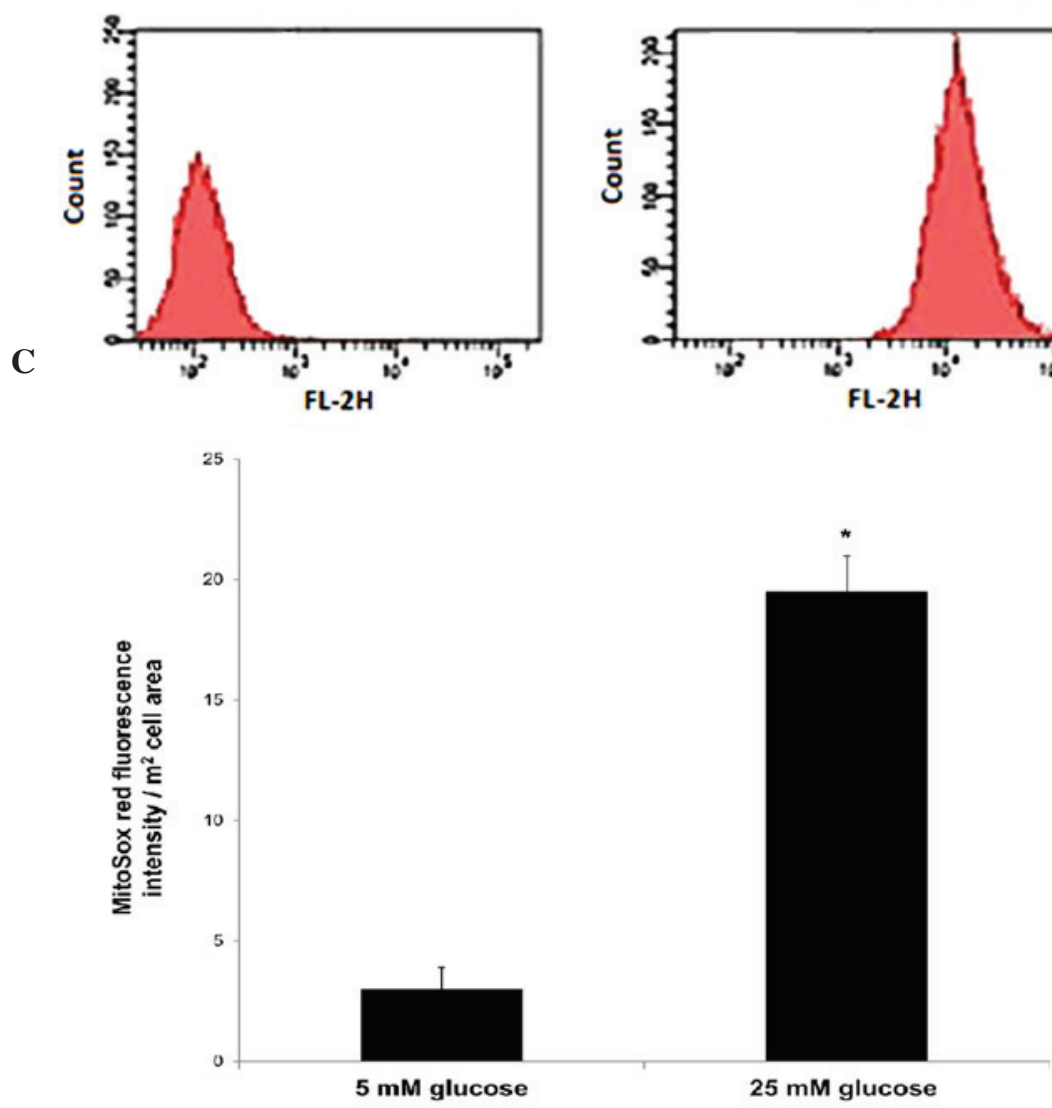

$25 \mathrm{mM}$ glucose

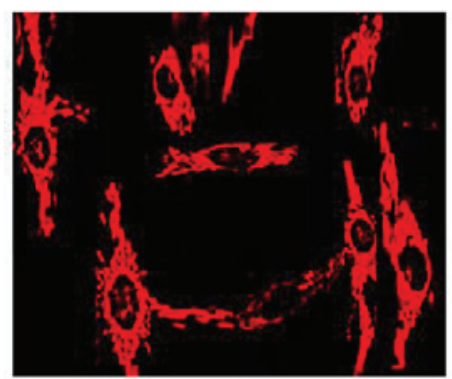

$25 \mathrm{mM}$ glucose

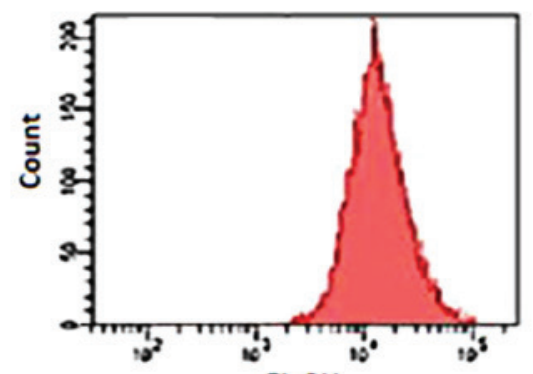

$\mathbf{F L}-\mathbf{2 H}$

Figure 1. High glucose induces an increase in mitochondrial ROS production in human renal mesangial cells. Synchronized quiescent cells grown on glass coverslips were incubated with 5 and $25 \mathrm{mM}$ glucose for $24 \mathrm{~h}$. The cells were loaded with MitoSOX red ( $5 \mu \mathrm{M}$ for $20 \mathrm{~min})$ and mitochondrial ROS was detected under a confocal microscope and by flow cytometry. (A) Representative confocal images (magnification, x63) of ROS generation in the cells, as MitoSOX red fluorescence. (B) Representative histograms of flow cytometry demonstrating the fluorescent intensity of MitoSOX red. (C) Quantitative analysis of MitoSox red fluorescence. Data are expressed as the mean \pm standard deviation of three experiments. ${ }^{*} \mathrm{P}<0.05$, vs. 5 mM glucose. ROS, reactive oxygen species.

High glucose increases the mRNA expression levels of mtDNA-encoded subunits of the ETC. The mRNA expression levels of mtDNA-encoded ND2, CYTB, COI and ATPase 6 relative to $\beta$-actin were determined using RT-qPCR in the human renal mesangial cells, following culture for $24 \mathrm{~h}$ in either $5 \mathrm{mM}$ glucose (normal glucose) or $25 \mathrm{mM}$ glucose (high glucose).

The cells grown in $25 \mathrm{mM}$ glucose showed significant increases in the mRNA expression levels of ND2, CYTB, COI and ATPase 6, compared with the cells incubated in $5 \mathrm{mM}$ glucose $(\mathrm{P}<0.05$; Fig. 2$)$. The relative mean mRNA expression levels of ND2, CYTB, COI and ATPase 6 were 2.3-fold

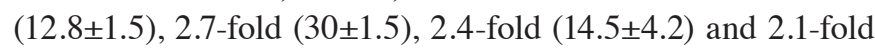
$(14.8 \pm 3)$ higher in the cells cultured in $25 \mathrm{mM}$ glucose, respectively, compared with the mRNA expression levels of ND2, CYTB, COI and ATPase 6 cultured in $5 \mathrm{mM}$ glucose $(5.5 \pm 2.3,11 \pm 0.53,6 \pm 0.5$ and $6.9 \pm 1.8$, respectively).

High glucose increases the protein expression levels of mtDNA-encoded subunits of ETC. In the same cells, the protein expression levels of mtDNA-encoded ND2, CYTB, COI and ATPase 6, normalized to $\beta$-actin, were determined using western blotting following incubation of the cells in $5 \mathrm{mM}$ glucose (normal glucose) and $25 \mathrm{mM}$ glucose (high glucose) for $24 \mathrm{~h}$.

Significant increases in the protein expression levels of ND2, CYTB, COI and ATPase 6 were also observed in the 


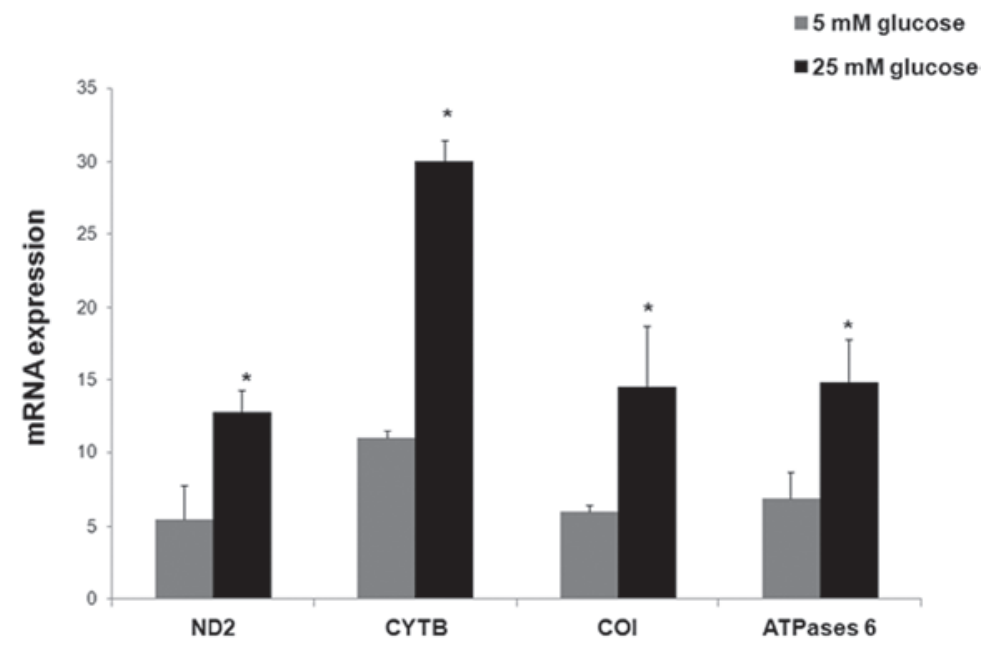

Figure 2. High glucose increases the mRNA expression levels of mtDNA-encoded subunits of the electron transport chain in human renal mesangial cells. Synchronized quiescent cells were incubated with 5 and $25 \mathrm{mM}$ glucose for $24 \mathrm{~h}$. The mRNA expression levels of mtDNA-encoded ND2, CYTB, COI and ATPase 6 relative to $\beta$-actin were determined using reverse transcription-quantitative polymerase chain reaction analysis. Data are expressed as mean \pm standard deviation from an average of three experiments. ${ }^{~} \mathrm{P}<0.05$, vs. $5 \mathrm{mM}$ glucose. ND2, nicotinamide adenine dinucleotide dehydrogenase 2 ; CYTB, cytochrome $b$; COI, cytochrome $c$ oxidase.

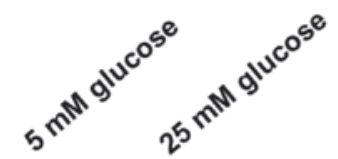

ND2

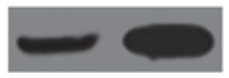

CYTB

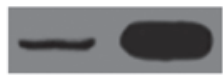

col

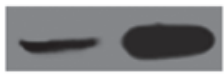

ATPases 6

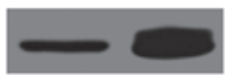

$\beta-$ actin
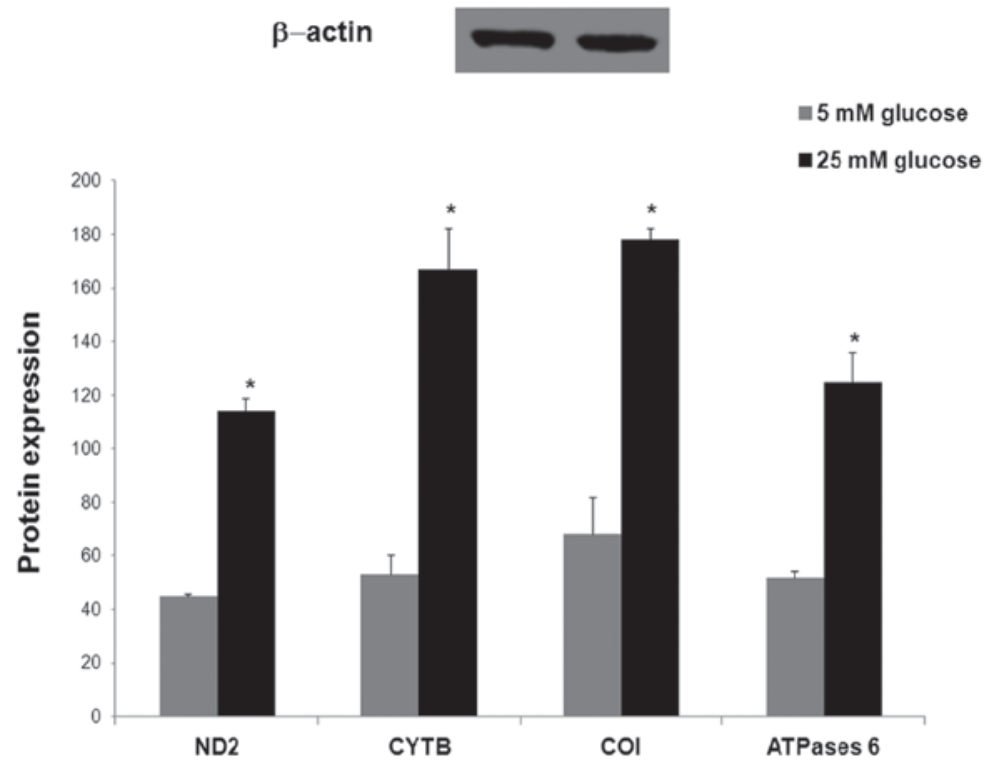

Figure 3. High glucose increases the protein expression levels of mtDNA-encoded subunits of the electron transport chain in human renal mesangial cells. Synchronized quiescent cells were incubated with 5 and $25 \mathrm{mM}$ glucose for $24 \mathrm{~h}$. The protein expression levels of mtDNA-encoded ND2, CYTB, COI and ATPase 6 normalized to $\beta$-actin were determined using western blot analysis. Data are expressed as mean \pm standard deviation from three experiments. ${ }^{*} \mathrm{P}<0.05$, vs. $5 \mathrm{mM}$ glucose. ND2, nicotinamide adenine dinucleotide dehydrogenase 2; CYTB, cytochrome $b$; COI, cytochrome $c$ oxidase. 
cells cultured in $25 \mathrm{mM}$ glucose, compared with the levels observed in the cells cultured in $5 \mathrm{mM}$ glucose $(\mathrm{P}<0.05$; Fig. 3$)$. The relative mean protein expression levels of ND2, CYTB, COI and ATPase 6 were 2.5-fold (114 \pm 5$)$, 3.2-fold (167 \pm 15.4$)$, 2.6-fold (178 \pm 4.2$)$ and 2.4-fold $(125 \pm 11)$ higher in the $25 \mathrm{mM}$ glucose-treated cells, respectively, compared with the protein expression levels of ND2, CYTB, COI and ATPase 6 in the $5 \mathrm{mM}$ glucose-treated cells $(45 \pm 1,53 \pm 7.5,68 \pm 13.8$ and $52 \pm 2.6$, respectively).

\section{Discussion}

The present study examined changes in the gene expression levels of subunits of the ETC complexes encoded by mtDNA in human renal mesangial cells in response to high glucose-induced reactive oxygen species (ROS) overproduction. The results of the present study demonstrated that high glucose induced an increase in mitochondrial ROS levels, as detected by the increased fluorescence intensity of the specific mitochondrial MitoSOX red probe. This increase in fluorescence intensity was not detected in the normal glucose-treated cells. In addition to the increase in ROS generation, an increase in the mRNA expression levels of mtDNA-encoded ND2 of complex I, CYTB of complex III, COI of complex IV and ATPase 6 of complex V were observed in the high glucose-cultured cells, compared with the cells treated with normal glucose. These increases were accompanied by increases in the expression levels of their corresponding proteins in the high glucose cultured cells. These results suggested that increased gene expression of mtDNA-encoded subunits of the ETC in human renal mesangial cells is the consequence of elevated mitochondrial ROS production induced by high glucose.

Mitochondria are important intracellular organelles, which supply energy to cells, and are also the major intracellular source of ROS (22). Superoxide is the first free radical produced as mitochondrial derived-ROS, and is a highly reactive species, which does not diffuse readily throughout the cell $(9,23)$. mtDNA encodes essential components of complexes of the ETC, as well as the ribosomal and transfer RNAs necessary for protein production within the mitochondria, and its maintenance is vital for proper cellular function $(6,7)$. The ROS generated by mitochondria can cause defects in the mtDNA and mitochondrial components, and thus may lead to mitochondrial dysfunction $(7,8)$.

High glucose elicits the overproduction of ROS via the mitochondrial ETC during respiration (1), and increased superoxide production via the mitochondrial respiratory chain has been shown to be the causal link between high glucose and the signaling pathways responsible for hyperglycemic tissue damage, which leads to the complications in diabetes, including diabetic nephropathy $(1,4)$.

Enhanced ROS production and oxidative stress have been reported in several pathological conditions in which the respiratory chain is impaired, including neurodegenerative diseases $(9-11,24)$, cancer $(12,24)$ and diabetes $(15,16)$. Furthermore, the aging process in humans has been shown to be associated with an increase in mitochondrial abundance, mtDNA copy number and the expression levels of respiratory genes, as a compensatory response for defective mitochondria and mtDNA damage $(13,14,25)$.
Our previous study on human renal mesangial cells also showed that high glucose induces an increase in mtDNA copy number in response to oxidatively damaged mtDNA due to increased mitochondrial ROS, which was prevented by normalizing the levels of mitochondrial ROS (18). The results of the present study demonstrated increased ROS production in high glucose-treated human renal mesangial cells. In addition to ROS overproduction, increases in mtDNA-encoded gene expression levels of important subunits of ETC complexes were observed.

The increased expression levels of mitochondrial-encoded genes has been shown to be associated with mtDNA damage and mitochondrial dysfunction in human cardiomyopathy (26), as well as in the pathogenicity of diabetes mellitus (27). In vitro studies using cultured vascular endothelial and smooth muscle cells have demonstrated that ROS mediate mtDNA damage and alterations of gene expression, and impair mitochondrial function (28). Altered gene expression levels of the mitochondrial ETC complexes due to enhanced mitochondrial ROS production have also been reported in retinal endothelial cells cultured under high glucose conditions (29), and have been associated with mtDNA oxidative damage and mitochondrial dysfunction in animal and experimental models of diabetic retinopathy (30).

Ide et al (31) demonstrated that increases in ROS production are associated with mitochondrial damage and dysfunction in myocardial infarction, which leads to a cyclic increase in ROS production, mitochondrial damage and cellular injury.

Furthermore, high glucose-induced oxidative damage to mtDNA and mitochondria has been shown to induce early vascular damage in diabetic retinopathy by initiating a cycle of mitochondrial functional decline, increased ROS generation and further mtDNA damage (32).

The increase in mRNA expression levels of mtDNA-encoded complexes of the respiratory chain in human renal mesangial cells observed in the present study may be a feedback response for defective mtDNA and mitochondria, mediated by high glucose-induced ROS levels, to allow the production of proteins involved in the ETC at higher levels and counteracting mitochondrial functional decline.

Although the present study examined changes in the expression levels of mtDNA-encoded genes following exposure of human mesangial cells to high glucose for $24 \mathrm{~h}$, further investigations with the aim to examine the chronic effect of high glucose-induced ROS levels on mitochondrial-encoded gene expression and mitochondrial function in diabetic nephropathy are underway.

In conclusion, the present study demonstrated for the first time, to the best of our knowledge, that the gene expression levels of certain subunits of the ETC complexes encoded by mtDNA were increased in human renal mesangial cells in response to high glucose-induced ROS overproduction, to compensate for mitochondrial dysfunction. High glucose-induced defective mitochondria may be important in the development and progression of diabetic nephropathy through enhanced ROS generation.

\section{Acknowledgements}

The authors of the present study would like to thank the Research Unit at the Department of Molecular Medicine, 
Al-Jawhara Centre, College of Medicine and Medical Sciences, Arabian Gulf University, Bahrain for the technical and financial support. The present study was supported by a departmental fund from the College of Medicine and Medical Sciences (Arabian Gulf University).

\section{References}

1. Brownlee M: Biochemistry and molecular cell biology of diabetic complications. Nature 414: 813-20, 2001.

2. Nohl H: Generation of superoxide radicals as byproduct of cellular respiration. Ann Biol Clin (Paris) 52: 199-204, 1994.

3 . Turrens JF: Superoxide production by the mitochondrial respiratory chain. Biosci Rep 17: 3-8, 1997.

4. Nishikawa T, Edelstein D, Du XL, Yamagishi S, Matsumura T, Kaneda Y, Yorek MA, Beebe D, Oates PJ, Hammes HP, et al: Normalizing mitochondrial superoxide production blocks three different pathways of hyperglycemic damage. Nature 404: 787-790, 2000.

5. Anderson S, Bankier AT, Barrell BG, de Bruijn MH, Coulson AR, Drouin J, Eperon IC, Nierlich DP, Roe BA, Sanger F, et al: Sequence and organization of the human mitochondrial genome. Nature 290: 457-65, 1981.

6. Taanman JW: The mitochondrial genome: Structure, transcription, translation and replication. Biochim Biophys Acta 1410: 103-123, 1999.

7. Bohr VA: Repair of oxidative DNA damage in nuclear and mitochondrial DNA, and some changes with aging in mammalian cells. Free Radic Biol Med 32: 804-812, 2002.

8. Santos JH, Hunakova L, Chen Y, Bortner C and Van Houten B Cell sorting experiments link persistent mitochondrial DNA damage with loss of mitochondrial membrane potential and apoptotic cell death. J Biol Chem 278: 1728-1734, 2003.

9. Kirkinezos IG and Moraes CT: Reactive oxygen species and mitochondrial diseases. Semin Cell Dev Biol 12: 449-457, 2001.

10. Gu XM, Huang HC and Jiang ZF: Mitochondrial dysfunction and cellular metabolic deficiency in Alzheimer's disease. Neurosci Bull 28: 631-640, 2012.

11. Hauser DN and Hastings TG: Mitochondrial dysfunction and oxidative stress in Parkinson's disease and monogenic parkinsonism. Neurobiol Dis 51: 35-42, 2013.

12. Boland ML, Chourasia AH and Macleod KF: Mitochondrial dysfunction in cancer. Front Oncol 3: 292, 2013.

13. Manczak M, Jung Y, Park BS, Partovi D and Reddy PH: Time-course of mitochondrial gene expressions in mice brains: Implications for mitochondrial dysfunction, oxidative damage and cytochrome $\mathrm{c}$ in aging. J Neurochem 92: 494-504, 2005.

14. Lee HC and Wei YH: Mitochondrial role in life and death of the cell. J Biomed Sci 7: 2-15, 2000.

15. Raza H, Prabu SK, John A and Avadhani NG: Impaired mitochondrial respiratory functions and oxidative stress in streptozotocin-induced diabetic rats. Int J Mol Sci 12: 3133-3147, 2011

16. Rolo AP and Palmeira CM: Diabetes and mitochondrial function: Role of hyperglycemia and oxidative stress. Toxicol Appl Pharmacol 212: 167-178, 2006.
17. Munusamy S, Saba H, Mitchell T, Megyesi JK, Brock RW and MacMillan-Crow LA: Alteration of renal respiratory Complex-III during experimental type-1 diabetes. BMC Endocr Disord 9: 2, 2009.

18. Al-Kafaji G and Golbahar J: High glucose-induced oxidative stress increases the copy number of mitochondrial DNA in human mesangial cells. Biomed Res Int 2013: 754946, 2013.

19. Al-Kafaji G and Malik AN: Hyperglycemia induces elevated expression of thyroid hormone binding protein in vivo in kidney and heart and in vitro in mesangial cells. Biochem Biophys Res Commun 391: 1585-1591, 2010.

20. Malik AN and Al-Kafaji G: Glucose regulation of beta-defensin-1 mRNA in human renal cells. Biochem Biophys Res Commun 353: 318-323, 2007.

21. Al-Kafaji G, Sabry MA and Skrypnyk C: Time-course effect of high-glucose-induced reactive oxygen species on mitochondrial biogenesis and function in human renal mesangial cells. Cell Biol Int: Aug 6, 2015 (Epub ahead of print).

22. Murphy MP: How mitochondria produce reactive oxygen species. Biochem J 417: 1-13, 2009.

23. Esposito LA, Melov S, Panov A, Cottrell BA and Wallace DC: Mitochondrial disease in mouse results in increased oxidative stress. Proc Natl Acad Sci USA 96: 4820-4825, 1999.

24. Enns GM: The contribution of mitochondria to common disorders. Mol Genet Metab 80: 11-26, 2003.

25. Lee HC and Wei YH: Mitochondrial biogenesis and mitochondrial DNA maintenance of mammalian cells under oxidative stress. Int J Biochem Cell Biol 37: 822-834, 2005.

26. Ahuja P, Wanagat J, Wang Z, Wang Y, Liem DA, Ping P, Antoshechkin IA, Margulies KB and MacLellan WR: Divergent mitochondrial biogenesis responses in human cardiomyopathy. Circulation 127: 1957-1967, 2013.

27. Antonetti DA, Reynet C and Kahn CR: Increased expression of mitochondrial-encoded genes in skeletal muscle of humans with diabetes mellitus. J Clin Invest 95: 1383-1388, 1995.

28. Ballinger SW, Patterson C, Yan CN, Doan R, Burow DL, Young CG, Yakes FM, Van Houten B, Ballinger CA, Freeman BA and Runge MS: Hydrogen peroxide- and peroxynitrite-induced mitochondrial DNA damage and dysfunction in vascular endothelial and smooth muscle cells. Circ Res 86: 960-966, 2000.

29. Madsen-Bouterse SA, Zhong Q, Mohammad G, Ho YS and Kowluru RA: Oxidative damage of mitochondrial DNA in diabetes and its protection by manganese superoxide dismutase. Free Radic Res 44: 313-321, 2010.

30. Santos JM, Tewari S, Goldberg AF and Kowluru RA: Mitochondria biogenesis and the development of diabetic retinopathy. Free Radic Biol Med 51: 1849-1860, 2011.

31. Ide T, Tsutsui H, Hayashidani S, Kang D, Suematsu N, Nakamura K, Utsumi H, Hamasaki $\mathrm{N}$ and Takeshita A: Mitochondrial DNA damage and dysfunction associated with oxidative stress in failing hearts after myocardial infarction. Circ Res 88: 529-535, 2001

32. Xie L, Zhu X, Hu Y,Li T, Gao Y, Shi Y and Tang S: Mitochondrial DNA oxidative damage triggering mitochondrial dysfunction and apoptosis in high glucose-induced HRECs. Invest Ophthalmol Vis Sci 49: 4203-4209, 2008. 